\title{
REACTIVE OXYGEN SPECIES (ROS) - A FAMILY OF FATE DECIDING MOLECULES PIVOTAL IN CONSTRUCTIVE INFLAMMATION AND WOUND HEALING
}

\author{
Nicholas Bryan ${ }^{1 *}$, Helen Ahswin², Neil Smart ${ }^{3}$, Yves Bayon ${ }^{2}$, Stephen Wohlert ${ }^{2}$ and John A. Hunt ${ }^{1}$ \\ ${ }^{1}$ Clinical Engineering, UKCTE, UKBioTEC, The Institute of Ageing and Chronic Disease, University of Liverpool, \\ Duncan Building, Daulby Street, Liverpool, L69 3GA, UK \\ ${ }^{2}$ Covidien - Sofradim Production, 116 Avenue du Formans - BP132, F-01600 Trevoux, France \\ ${ }^{3}$ Royal Devon \& Exeter Hospital, Barrack Road, Exeter, Devon, EX2 5DW, UK
}

\begin{abstract}
Wound healing requires a fine balance between the positive and deleterious effects of reactive oxygen species (ROS); a group of extremely potent molecules, rate limiting in successful tissue regeneration. A balanced ROS response will debride and disinfect a tissue and stimulate healthy tissue turnover; suppressed ROS will result in infection and an elevation in ROS will destroy otherwise healthy stromal tissue. Understanding and anticipating the ROS niche within a tissue will greatly enhance the potential to exogenously augment and manipulate healing.

Tissue engineering solutions to augment successful healing and remodelling of wounded or diseased tissue rely on a controlled balance between the constructive and destructive capacity of the leukocyte secretome, including ROS.

This review comprehensively considers leukocyte derived ROS in tissue repair with particular interest in surgical intervention with inclusion of a biomaterial. The article considers ROS fundamental chemistry, formation, stimulation and clearance before applying this to discuss the implications of ROS in healing tissue with and without a biomaterial. We also systematically discuss ROS in leukocyte signalling and compare and contrast experimental means of measuring ROS.
\end{abstract}

Keywords: Reactive oxygen species; inflammation; wound healing; leukocytes; pattern recognition receptors; cell signalling; biomaterials.

\footnotetext{
* Address for correspondence:

Nicholas Bryan

University of Liverpool - School of Clinical Sciences

UK Centre for Tissue Engineering Ground Floor

Duncan Building, Daulby Street

Liverpool L69 3GA, UK
}

E-mail: n.bryan@liv.ac.uk

\section{Introduction}

The survival and longevity of any animal requires an active vigilant set of defence mechanisms to combat infection, efficiently repair damaged tissue and remove debris associated with apoptotic/necrotic cells. Compromised tissue rapidly results in decreased mobility, organ failures, hypovolaemia, hypermetabolism, and ultimately infection and sepsis. Therefore, mammals have evolved an array of physiological pathways and mechanisms that enable damaged tissue to return to a basal homeostatic state. In an ideal scenario this occurs without compromise of tissue mechanics, scarring or incorporation of microbial material.

Leukocytes are a fulcrum in the positive and negative feedback systems of the multivariate wound healing response (Wilgus, 2008). Through a highly complex extracellular signalling network coupled with a dynamic array of surface receptors these cells drive the host through tissue imbalances to stabilisation. At the most fundamental level, professional phagocytes - macrophages and neutrophils - debride compromised tissue, internalising and destroying pathogens in a series of controlled cytoplasmic explosions. As the wound site is cleared, building blocks are assembled for repair, and the same cells take on a more constructive role, orchestrating proliferation of stromal cells to repair the damaged area. Away from the wound, systemically some of these phagocytes drain and migrate through the lymphatic system to begin the unimaginable sophistication of antigen presentation, introducing into the healing milieu exquisite specificity and targeted microbial eradication from T and B lymphocytes (Witko-Sarsat et al., 2000; Park and Barbul, 2004; Szpaderska and DiPietro, 2005; Nathan, 2006; Tsirogianni et al., 2006; Emming et al., 2009; Kumar and Sharma, 2010).

To further compound the complexity of wound healing, inflammatory cells may also be presented with the challenge of a foreign body in the form of a medical device or implanted biomaterial. A large acute leukocyte interaction can have significant effects on the longevity and efficacy of the material itself; it can cause a vastly accelerated degradation profile, loss of mechanical integrity and poor integration with healthy tissues. Therefore, understanding the mechanisms and pathways by which leukocytes interact with implantable materials is a paramount deliverable during their engineering and fabrication phases (Devereux et al., 1990; Sutherland et al., 1993; Babensee et al., 1998; Nygren et al., 2001; Mizuki et al., 2005; Kader and Coyle, 2007; Anderson et al., 2008; 
Jeannin et al., 2008; Brown and Griendling, 2009; Franz et al., 2011).

Leukocytes of the professional phagocyte class (monocytes, neutrophils and dendritic cells) possess numerous molecular bactericidal mechanisms which occur both inside and outside of the cell, with potential for catastrophic damage to otherwise healthy native tissue without appropriate regulation. During phagocytosis of invading organisms leukocytes rapidly increase their consumption of molecular oxygen, in a process referred to as the respiratory burst. This arms the most destructive weapons in the phagocyte's arsenal: reactive oxygen species (ROS) (Nathan and Shiloh, 2000). This short-lived group of incredibly cytotoxic molecules form an integral part of the phagosome. By means of a controlled generation on the inner phagosomal membrane the ROS rapidly degenerate internalised pathogens. However, ROS are also secreted into interstitial fluids where their beneficial role in focal sterilisation of the extracellular environment may be over-shadowed by their destructive influence to otherwise healthy tissue.

ROS is an umbrella term, comprising radicals and unstable oxygen containing molecules with the propensity to easily form radicals. Collectively, this group of molecules contain one or more unpaired electrons making them extremely susceptible to interaction with biological polymers such as protein, DNA, lipids and carbohydrates (Buonocore et al., 2010). ROS have a fundamental function in innate immunity and form the first line of defence against invading organisms. Indeed, no ROS review article would be complete without paying homage to chronic granulomatous disease (CGD) - an inherited condition in which sufferers lack a respiratory burst response. CGD patients are massively susceptible to bacterial and fungal infections during the acute phase of inflammation and before the advancement of antibiotics, typically died within the first year of life. Studying cells isolated from CGD patients allowed huge leaps to be made in elucidating the molecular mechanisms of ROS generation in leukocytes (Henderson and Chappell, 1996; Cooper et al., 2000).

Human disease states may also arise downstream of ROS production. Pathologies as diverse as joint diseases, asthma, cancer, obesity and neurodegeneration can all be influenced by the improper functioning of the ROS processing enzyme superoxide dismutase (SOD), the functions and significance of which will be discussed in detail throughout this review (Janssen-Heininger et al., 2005; Johnson and Giulivi, 2005; Afonso et al., 2007).

ROS play a role in a number of physiologic processes throughout an organism; their ubiquitous nature throughout all mammalian tissues has highlighted malfunctions in their production as a potential route of tumourigenesis (Storz, 2005), and lead to considering molecules which target various components of the ROS production system as candidate anti-cancer chemotherapeutic agents (Ferguson et al., 2005). Further to fundamental host defence, ROS also play pivotal roles in cell signalling, wound debridement and clearance of apoptotic/necrotic cells throughout tissue remodelling. Typically considered as brutal, vigilante molecules during inflammation, the cell signalling effects of ROS are often overlooked in favour of the much more elegant cellular proteinaceous language of chemokines and growth factors. However, ROS also play an important role in conveying the progression of wound healing throughout the inflammasome by means of both paracrine and second messenger roles.

This comprehensive review will focus on defining the role of ROS in healing tissue, discuss in detail the main route of ROS formation in phagocytes and how ROS are able to execute their physiologic functions as both antimicrobial and cell signalling molecules, with particular interest to their impact in tissue regeneration in conjunction with the inclusion of a biomaterial.

\section{ROS Synthesis}

Although ROS can be produced by a number of cytoplasmic enzymes - including xanthine oxidase, lipoxygenase, cycloxgenase and nitric oxide synthase - in addition to numerous aspects of mitochondrial physiology, most of the phagocyte ROS derive from superoxide generated by NADPH oxidase. This multimeric membrane bound electron-transfer complex is the main site of ROS formation in phagocytes and undergoes multiple modifications to its intercellular component to functionalise during leukocyte activation.

The two membrane spanning proteins of the NADPH complex; p22 $2^{\text {phox }}$ and gp91 ${ }^{\text {phox }}(\mathrm{NOX} 2)$ are the catalytic components of the enzyme, ever present on the phagocyte cell membrane, collectively referred to as cytochrome $\mathrm{b}_{558}$. Upon phagocyte activation, the cytosolic regulatory elements $\mathrm{p} 47^{\text {phox }}, \mathrm{p} 67^{\text {phox }}$ and $\mathrm{p} 40^{\text {phox }}$ translocate and associate with cytochrome $\mathrm{b}_{558}$. Simultaneously to the phox (phagocyte oxidase) moieties, the GTPase cofactor rac2 also translocates to the plasma membrane after dissociation from its repressor RhoGDI by Rac guanine nucleotide exchange factor and interacts directly with p6 $7^{\text {phox }}$. The association of rac2 in combination with phosphorylation of multiple activation loci on $\mathrm{p} 47^{\text {phox }}$ by the MAPKs (mitogen associated protein kinases) ERK (extracellular signal regulated protein kinase) and p38 produces the actively reducing NADPH complex with suitably intricate biochemistry to ensure that ROS are only synthesised in the presence of appropriate stimuli (Henderson and Chappell, 1996; Dahlgren and Karlsson, 1999; Diebold and Bokoch, 2001; Nygren et al., 2001; Groemping et al., 2003; Mizuki et al., 2005; Bokoch and Zhao, 2006; Lam et al., 2010).

The NADPH oxidase complex is not specific to phagocytes with many mammalian cell types expressing various forms. Tissue specific NADPH oxidases differ with respect to their NOX/DUOX (dual oxidase) isoform of which 7 exist with varying tissue distributions. Interestingly, a single cell can possess multiple NADPH complexes containing differing NOX components suggesting different downstream signalling of alternative NOX containing NADPH complexes (Brown and Griendling, 2009). NADPH assembly signals may include classical PAMPs (pathogen associated molecular patterns) such as LPS, soluble peptides with specific recognition 
receptors such as f met-leu-phe (fMLP), complement, lectins, chemotaxins or through interaction with humeral immunity via $\mathrm{F}_{c}$ receptors activated by opsonised pathogen or pathogenic membrane constituents. NADPH oxidase produces superoxide via a two-step process. The initiation reaction occurs when an electron is transferred from NADPH to flavin adenine dinucleotide (FAD) located at the $\mathrm{C}$ terminus of gp91 ${ }^{\text {phox }}$. This electron transfers to a haeme moiety contained within $\mathrm{p} 22^{\text {phox }}$ which then interacts with molecular oxygen to result in superoxide. This reaction can be summarised as:

$$
\mathrm{NADPH}+2 \mathrm{O}_{2} \rightarrow \mathrm{NADP}^{+}+2 \mathrm{O}_{2}^{-}+2 \mathrm{H}^{+}
$$

Cytochrome $\mathrm{b}_{558}$ is an exclusively membrane bound complex. However, its presence is not specifically restricted to membranes that contact the extracellular environment. Cytochrome $b_{558}$ also occurs in the membranes of numerous intracellular structures.

Neutrophils, possess at least 4 different types of granules within their cytoplasm. These can be subcategorised into azurophilic, gelatinase, secretory and specific granules and contain an array of bactericidal molecules. Granules can fuse with the phagosome to secrete their payload directly onto captured pathogens or integrate with the plasma membrane to elute their contents into the extracellular space. In this instance, granule membranes also act as a sink for surface receptors, incorporating a new series of activation receptors onto the cell surface during their fusion (Nathan, 2006).

Neutrophil granules, particularly those of the specific and gelatinase subclasses, possess abundant cytochrome $\mathrm{b}_{558}$ within their membranes (total neutrophil cytochrome $\mathrm{b}_{558}$; plasma membrane: granule membrane $5 \%: 95 \%$ ). This compounds the granules' cytotoxicity to internalised pathogens. When a granule fuses with the phagosome to incorporate its lytic payload, the membrane fusion also increases the phagosomal NADPH oxidase concentration and resultant ROS release (Dahlgren and Karlsson, 1999).

\section{Further ROS Formation}

The formation of superoxide by NADPH oxidase is the initiation reaction for the formation of further ROS within the cytoplasm and extracellular spaces. Hydrogen peroxide $\left(\mathrm{H}_{2} \mathrm{O}_{2}\right)$ is formed by spontaneous dismutation of superoxide in addition to enzymatically regulated conversion by superoxide dismutase (SOD). $\mathrm{H}_{2} \mathrm{O}_{2}$ is a weak oxidising agent. However, a Fenton reaction with iron yields hydroxyl $(-\mathrm{OH})$ radicals, the most oxidising of all cellular ROS.

$\mathrm{H}_{2} \mathrm{O}_{2}$ is converted into hypohalous acids such as hypochlorite $\left(\mathrm{OCl}^{-}\right)$by reaction with $\mathrm{Cl}^{-}$catalysed the lysosomal haeme containing enzyme myeloperoxidase stored inside neutrophil azurophilic granules. The result of this can be increased phagosome cytotoxicity as a result of granule/phagosome fusion, $\mathrm{OCl}^{-}$containing granules by transmembrane diffusion of $\mathrm{H}_{2} \mathrm{O}_{2}$ directly into azurophilic granules, or elution of $\mathrm{OCl}^{2}$ into the extracellular inflammatory milieu by granule fusion with the plasma membrane. Hypochlorite can then undergo secondary reactions with $\mathrm{H}_{2} \mathrm{O}_{2}$ and amines to produce singlet oxygen and chloramines.

Reaction of superoxide with nitric oxide produced by inducible nitric oxide synthase (iNOS) yields peroxynitrite $\left(\mathrm{ONOO}^{-}\right)$which can undergo further spontaneous reaction with carbonyl compounds to produce a number of organic peroxyl radicals. The components of the nitrogenous arm of additional ROS reactions are referred to broadly as reactive nitrogen species (RNS) (Brown and Griendling, 2009).

\section{ROS Detoxification}

The lack of specificity of ROS towards particular bacterial molecules, coupled with their ability to be secreted into the extracellular milieu rather than solely retained in the phagosome, means that these molecules can exert their cytotoxic properties on healthy native tissue if appropriate systems are not in place to safely detoxify them. Furthermore, generation of reactive oxygen metabolites is an unavoidable by-product of respiration. Therefore, biochemical systems by which ROS can be disposed are vital to the survival of an organism. ROS detoxification can occur in a number of ways and genomically is controlled by a diverse series of transcription factors including peroxisome proliferator-activated receptor- $\gamma$ (PPAR $\gamma$ ), p53, activating transcription factor 4 (ATF4) and nuclear factor-erythroid 2 related factor 2 (Nrf2) (Maher and Yamamoto, 2010). There are enzymatic systems in place which decrease the potency of particular reactive species, or render them completely harmless. Alternatively, ROS can interact with antioxidants such as vitamins, glutathione or proteins, particularly those with metal ion moieties capable of oxidation/reduction reactions - such as the iron present in transferrin and ferritin (Limon-Pacheco and Gosebatt, 2009).

$\mathrm{SOD}$, by virtue of the fact it converts $\mathrm{O}_{2}{ }^{-}$into less potent $\mathrm{H}_{2} \mathrm{O}_{2}$, is considered a ROS detoxification enzyme. Three isoforms of SOD exist, intracellular $\mathrm{Cu} / \mathrm{Zn} \mathrm{SOD}$ (SOD1), extracellular $\mathrm{Cu} / \mathrm{Zu}$ SOD (SOD3) and MnSOD (SOD2) which is predominantly located in the mitochondria. In addition to detoxification, SOD is an important enzyme in facilitating the signalling properties of ROS. This because $\mathrm{H}_{2} \mathrm{O}_{2}$, due to its relatively long half-life compared to other cellular oxidants and its ability to traverse membranes, is the optimal signalling candidate derived from NADPH oxidase (Fattman et al., 2003; Zelko et al., 2002).

Catalase 'picks up the baton' from SOD in the race to rid tissues of damaging ROS. Catalase is a haemecontaining enzyme which is expressed throughout numerous tissues of the body, it decomposes $\mathrm{H}_{2} \mathrm{O}_{2}$ into water and molecular oxygen. This enzyme is most often found within intracellular organelles, such as peroxisomes, and therefore relies on the diffusion of $\mathrm{H}_{2} \mathrm{O}_{2}$ into these compartments to undergo detoxification (Nishikawa et al., 2009).

$\mathrm{H}_{2} \mathrm{O}_{2}$ can also be decomposed into water by enzymes of the glutathione peroxidase (GPx) family. In humans, there are $8 \mathrm{GPx}$ isoforms with varying tissue and substrate specificities. Typically, GPx enzymes are selenoproteins 
(GPx1-4 and GPx6, depending on species). In the context of NADPH derived oxidant detoxification, GPx catalyses the removal of $\mathrm{H}^{+}$from $\mathrm{H}_{2} \mathrm{O}_{2}$ to oxidise glutathione $(\mathrm{GSH})$ to glutathione disulphide (GS-SG) and reduce the $\mathrm{H}_{2} \mathrm{O}_{2}$ to water. Glutathione reductase then converts GS-SG back to reduced GSH via NADPH (Toppo et al., 2009). Absence of this enzyme renders cells in vitro hyper-susceptible to $\mathrm{H}_{2} \mathrm{O}_{2}$ induced cell death (De Haan et al., 2004; Johnson and Giulivi, 2005).

Peroxiredoxins are an additional class of 6 ROS detoxification enzymes, with the propensity to convert $\mathrm{H}_{2} \mathrm{O}_{2}$ to water. To a lesser extent, these enzymes also possess the ability to break down ONOO-. The peroxiredoxins are a prevalent group of enzymes, found mainly in the cytosol; these proteins comprise $0.1-0.8 \%$ of the total soluble protein found in mammalian cells (Wood et al., 2003).

\section{ROS Triggers}

Phagocytes can be induced to release extra ROS - and intracellularly, by a number of activation signals both with and without accompanying phagocytosis. These triggers are an amalgamation of molecular binding events which may be encountered as a consequence of infection, wounding, disease or administration of a foreign material during surgery. An unavoidable component of surgery is the mechanical manipulation and associated trauma to healthy and/or previously compromised tissues. This results in the secretion of numerous damage associated signals from stroma, in addition to release of the intercellular components of mechanically lysed cells into the wound milieu. Immediately after delivery, an implanted device will adsorb serum proteins onto its surface including Ig and complement - which also have the propensity to compound the overall inflammatory reaction elicited by the surgical procedure. All of these factors represent potential pathways for ROS stimulation whilst also highlighting the importance of considering ROS throughout the fabrication stages of a biomaterial. Both of these aspects will be discussed in further detail in the sections which follow.

\section{$\mathrm{F}_{\mathrm{c}}$ Receptors ( $\left.\mathrm{F}_{\mathrm{c}} \mathbf{R s}\right)$}

In vivo, materials and foreign particles become coated with immunoglobulins (Igs); this opsonisation process is part of the system which identifies substances and cells as being non-host and flags them for destruction and removal by cytotoxic inflammatory cells. $\mathrm{F}_{\mathrm{c}} \mathrm{Rs}$ are a complex class of molecules designated broadly into three classes $\left(\mathrm{F}_{\mathrm{c}} \alpha, \mathrm{F}_{\mathrm{c}} \gamma\right.$ and $\left.\mathrm{F}_{\mathrm{c}} \varepsilon\right)$ based the antibody class which they bind. They are further categorised into subtypes based on the precise antibody isotype with which they interact and the cell type on which they are found. $\mathrm{F}_{c} \gamma$ receptors (of which there are three subclasses $\mathrm{F}_{\mathrm{c}} \gamma \mathrm{RI}, \mathrm{F}_{\mathrm{c}} \gamma \mathrm{RII}$, and $\mathrm{F}_{c} \gamma \mathrm{RIII}$ ) are the most abundant $\mathrm{F}_{\mathrm{c}} \mathrm{R}$ on the surface of phagocytes and bind IgG. Collectively, phagocytes possess a huge compliment of $\mathrm{F}_{\mathrm{c}} \mathrm{Rs}$ - making them excitable by almost any form of opsonisation. In most cases $\mathrm{F} R$ binding causes phagocyte activation, with the exception of $\mathrm{F}_{c} \gamma \mathrm{RIIB}$ which inhibits leukocyte activation. Typically (although not exclusively, neutrophil $\mathrm{F}_{\mathrm{c}} \gamma \mathrm{RIIIB}$ is GPI anchored), $\mathrm{F} \gamma \mathrm{R}$ receptors are membrane spanning with an immunoreceptor tyrosine-based activation motif (ITAM) on the intercellular arm. ITAM phosphorylation, as a consequence of $\mathrm{F}_{c} / \mathrm{F}_{c} \gamma \mathrm{R}$ binding, triggers activation of numerous kinases and downstream signalling cascades including p38, ERK and JNK (c-jun N-terminal kinase) which mediate phagocytosis, NADPH oxidase assembly and ROS production (Indik et al., 1995; Nimmerjahn and Ravetch, 2008; Higurashi et al., 2012).

The downstream ROS elicited effects of $\mathrm{F}_{\mathrm{c}} \mathrm{R}$ binding can also present as a disease phenotype, for example in the condition Wegener's granulomatosis (WG). WG patients possess anti-neutrophil cytoplasmic antibodies (ANCA) typically towards the neutrophil serine protease PR3, which in WG is expressed on the neutrophil surface. The population of the neutrophil surface by ACNAs against PR3 causes cell activation by $\mathrm{F}_{c} \gamma \mathrm{RII}$, degranulation and subsequent vasculitis as a result of secreted ROS (Schilder, 2010).

\section{Complement}

Complement proteins are a small family of molecules which typically exist as pro-proteins in systemic circulation. Upon activation, they are cleaved into active forms by proteases such as C3-convertase which act in unison with $\mathrm{F}_{\mathrm{c}}$ mediated interactions with leukocytes to amplify the inflammatory response. Leukocytes possess surface receptors for numerous different complement components, binding of which results in cellular activation. $\mathrm{Mo} / \mathrm{M} \Phi$ lineage phagocytes possess the complement receptors; C5aR, C3aR, CR1, CR3/4, cC1qR, C1qRp. Neutrophils possess an identical receptor fingerprint with the inclusion of $\mathrm{gClqR}$. The genomic and transcriptomic events which precede complement receptor binding are less well defined than their $\mathrm{F}_{\mathrm{c}} \mathrm{R}$ equivalents, although possibly include the influence of protein kinase $\mathrm{C}$ and MAP kinases. Consequently, complement receptor activation results in pro-inflammatory signal transduction cumulating in phagocytosis, NADPH oxidase activation, ROS generation and neutrophil degranulation. It has been demonstrated that different complement receptors stimulate respiratory burst activity to varying amounts; one study in particular showed that $\mathrm{C} 3$ a stimulated a production of $\mathrm{H}_{2} \mathrm{O}_{2}$ at a rate 100 -fold less than if stimulated with C5a (Ehrengruber et al., 1994; Klegeris and McGeer, 1994; Leslie, 2010).

\section{Pattern Recognition Receptors (PRRs)}

Phagocytes possess a number of receptor classes, termed pattern recognition receptors (PRRs), which recognise and bind numerous highly conserved biomolecules. These include PAMPS (pathogen associated molecular patterns) that are associated with microbial threats, DAMPS (dangerassociated molecular patterns) that are associated with tissue damage or apoptotic cells and RAMPS (resolutionassociated molecular patterns) associated with wound healing (Shields, 2011). This PRR system allows specific and rapid destruction and antigen presentation of broad classes of infectious organisms or infected self, whilst the genomic recombination to create antigen specific lymphocyte support is underway in the thymus. 
Indeed, numerous pattern recognition receptors are dual functional - recognising both exogenous PAMP stimuli and endogenous DAMPs also (Jeannin et al., 2008). An example of this occurs during apoptosis, when macrophages specifically recognise apoptotic cells by their shuttling of 'eat me' signals to the cell surface including phosphatidyl serine (PS) which is acknowledged by specific PS receptors (Wu et al., 2006; Savill et al., 1993). Additional apoptotic cell signals also involve the modification of membrane lipids and proteoglycans which mimic PAMPS enabling PAMP receptor dual functionality, termed apoptotic cell associated molecular patterns (ACAMPs). However, apoptotic cell clearance via PAMP style endocytosis is typically associated with anti-inflammatory cytokine release such as IL-10, rather than pro-inflammation and ROS synthesis.

It is paramount to consider the role of PRRs in the activation of leukocytes by tissue based/biologic biomaterials such as the decellularised xenogeneic and allogeneic tissues used widely throughout surgery. Cellular remnants such as DNA and membrane fragments which remain in these materials, as a function of insufficiently stringent processing control, will play a part in cellular activation in response to their administration (Daly et al., 2012).

PRRs can be subdivided into numerous classes; for the purpose of this review focus will be on those specifically involved in phagocyte ROS production; Toll-like receptors, Nod-like receptors and c-type lectin receptors.

\section{Toll-like receptors (TLRs)}

These receptors are designated Toll-like receptors (TLRs) due to their homology with the Drosophila protein Toll. Phagocytes of the innate inflammatory system exhibit a conserved ability to recognise a diverse class of microbial molecules based on their TLR profile, with several TLRs demonstrating specificity with more than one microbial antigen.

TLRs have the ability to bind a diverse class of PAMP and DAMP antigens which include proteins, carbohydrates and nucleic acids. TLRs recognise extracellular PAMP antigens and intracellular antigens such as nucleic acids as part of the phagocytic process or during release from virally infected cells. Examples of PAMPs and their respective TLRs include lipoteichoic acid and mannan on gram negative bacteria and fungi respectively (TLR2+TLR6), prions (TLR2), lipopolysaccharide (LPS) (TLR4), flagellin (TLR5) and viral RNA (TLR7/8) (Kawai and Akira, 2007; Kumagai and Akira, 2010).

TLRs can recognise bacterial epitopes directly or through interaction with chaperones and accessory proteins. LPS recognition, for example, replies on a shuttling of soluble LPS by seromal LPS binding protein onto CD14 which then presents to and activates TLR4 (Defranco et al.,2007).

TLR stimulation results in a storm of intercellular transcription events which generally focus on promoting inflammatory cytokine production through NF- $\mathrm{kb}$. However, TLR activation also activates MAPKs, including p38, ERK and JNK pathways critical in NADPH oxidase assembly and function. In vitro studies have shown that
LPS stimulates ROS synthesis via TLR4-mediated Rac1 and NOX activation. This compounds the intracellular inflammatory signalling cascade by acting as second messengers for the classic redox dependent NF- $\kappa b$ proinflammatory pathway (Kasahara et al., 2011). Phagocyte killing of ubiquitous Staphylococcus aureus is contributed to an interaction with TLR2 which activates ROS production by trigger of $\mathrm{p} 47^{\text {phox }}$ phosphorylation, through a yet to be defined mechanism. This killing is independent of the classical p38 MAPK pathway and is thought to involve the interleukin-1 receptor kinase; IRAK4, highlighting the intracellular convergence of numerous extracellular binding events with the common outcome of ROS production (Jann et al., 2011).

MCP-1 (monocyte chemoattractant protein-1) is secreted by macrophages to recruit continuing waves of myeloid cell support to a wounded or healing tissue. Binding of TLR9 by bacterial nucleotide motifs stimulates macrophage MCP-1 release which has been shown to be via a ROS-dependant mechanism involving phospholipase $\mathrm{A}_{2}$, arachidonic acid and JNK, which ceases when NADPH oxidase is inhibited.

\section{Nod-like receptors}

Nucleotide binding oligomerisation domain (Nod)-like receptors are a family of intracellular PAMPs associated with infected self and endosomal microbial degeneration. NOD activation is typically associated with driving NF$\kappa \mathrm{b}$ and pro-caspase-1 inflammasomes and reports linking NOD-like receptor activation to specific ROS release are rare, although NLRX1 over-expression has been shown to enhance ROS production. NOD1 and NOD2 bind elements of peptidoglycan which is present in almost all bacteria. It has been demonstrated that stimulation of NOD2 leads to activation of p38 and ERK MAPKs which both play a function in NADPH oxidase activation, therefore making it reasonable to assume that NOD receptor stimulation by intracellular PAMPS could potentially result in ROS generation (Kanneganti et al., 2007; Philpott and Girardin, 2010).

\section{C-type lectin receptors}

C-type lectin receptors (CLRs) are a group of extracellular receptors expressed on $\mathrm{Mo} / \mathrm{M} \Phi$ lineage phagocytes and some subsets of stromal cells which typically, although not exclusively, recognise conserved prokaryotic carbohydrate motifs. These receptors can be broadly categorised into 2 classes, based on their ability to bind mannose or galactose type ligands. CLRs include the macrophage mannose receptor (CD206) which has the ability to bind numerous microbial membrane constituents including mannose (viruses, fungi bacterial), fucose (helminths, bacteria) and $\mathrm{N}$-acetyl glucosamine. Dectin-1 is possibly the most studied CLR on Mo/MФ cells, which recognises specific $\beta$-glucan motifs expressed on the surface of fungi (Herre et al., 2004). Binding of dectin-1 has been shown to result in ROS generation through syk (spleen tyrosine kinase) signalling. The inflammatory consequences of mannose receptor CD206 binding are much less defined with both pro- and anti-inflammatory events occurring as a consequence of the specific carbohydrate with which it 
interacts (McGreal et al., 2005; Osario and Reis e Sousa, 2011; Vautier et al., 2012).

\section{Nucleotide receptors}

Free nucleotides, particularly ATP are a classic DAMP; they are abundant in wound sites, by virtue of tissue damage resulting in cell lysis or are secreted by numerous cells throughout inflammation. Studies have demonstrated the capacity of extracellular nucleotides to stimulate ROS release from both macrophages and neutrophils. This occurs as a result of nucleotide interaction with P2 nucleotide surface receptors. The $\mathrm{P} 2$ receptors are a large family of surface molecules; broadly designated into P2X (ligand gated ion channels) and P2Y (G-protein coupled receptors). Particular interest has been designated to the $\mathrm{P} 2 \mathrm{X}_{7}$ receptor which has been shown to modulate a diverse set of inflammatory functions by activation of MAPKs which includes ROS release. Interestingly ADP has also been shown to trigger a respiratory burst in neutrophils through a mechanism which is independent of the MAPK ERK, in this instance implying PKC (protein kinase C) as the NADPH activating kinase (Gozal et al., 2001; Di Virgilio et al., 2001).

\section{Chemokine receptors}

The inflammatory milieu is abundant with soluble cytokines which are the primary language by which leukocytes and stromal cells communicate to manage the way in which a wound heals. Therefore, it is no surprise that the effects inflammatory cytokines exert on professional phagocytes often include a respiratory burst.

The catalytic gp91 phox $(\mathrm{NOX} 2)$ subunit of phagocyte NADPH oxidase is up-regulated in response to inflammatory cytokines. IFN $\gamma$ regulates gp9 $1^{\text {phox }}$ gene expression through both interferon regulatory factor1 (IRF1) and STAT1 binding of the interferon stimulated response elements located in the gp91 ${ }^{\text {phox }}$ promoter region. NF- $\kappa B$, a major downstream product of a multitude of leukocyte activation stimuli has also been demonstrated to up-regulate gp9 $1^{\text {phox }}$ transcription (Lambeth et al., 2007). Additional to ROS, previous studies have also demonstrated the ability of human Mo/MФ cells to increase their NOS synthesis in response to IFN $\gamma$ (Bose and Farina, 1995).

Cytokine activation of phagocytes does not necessarily involve classical inflammatory soluble molecules. Insulin has been demonstrated to increase phagocyte $\mathrm{O}_{2}{ }^{-}$ production through an NADPH oxidase dependent pathway which involves activation of ERK, p38 and NF- $\mathrm{BB}$ (San Jose et al., 2009).

In addition to the direct stimulation and upstream transcriptional regulation of NADPH by inflammatory molecules, cytokines also have the ability to 'prime' the respiratory burst. In this instance, the cytokine will not directly stimulate ROS release but will hypersensitise the cell to stimulation by a microbial ligand, resulting in a more rapid and amplified antimicrobial respiratory burst. This is the case with IL-8, which amplifies ROS release from neutrophils in response to stimulation with the bacterial peptide fMLP, however alone does not stimulate ROS release unless used in stochastically high concentrations (Brechard et al., 2008). It was shown that this is a consequence of IL-8 mediating an influx of intracellular $\mathrm{Ca}^{2+}$, although the precise molecular mechanism of NADPH activation was not defined. This priming role is also true of IL-12 which has been shown to augment the ROS response of primary leukocytes to opsonised zymosan (Yano et al., 2003). TNF $\alpha$ and GM-CSF have also been shown to prime neutrophils in a manner which involves phosphorylation of 4 $^{\text {phox }}$ resulting in conformational changes required for NADPH oxidase activation. Interestingly, these two chemokines have completely different surface receptors but both prime by the same mechanism. G-CSF and IL-1 $\beta$ do not cause $\mathrm{p} 47^{\text {phox }}$ phosphorylation and prime to a much smaller extent (Dewas et al., 2003; Tarr et al., 2003).

$\mathrm{TNF} \alpha$ is also a potent primer of phagocyte reparatory burst. In polymorphonuclear cells this is through a p38 MAPK mediated process in which intracellular granules containing cytochrome $\mathrm{b}_{558}$ exocytose, increasing the expression of in-tact NADPH oxidase on the cell surface (Ward et al., 2000b).

The interaction of cytokines with inflammatory cells may also inhibit or suppress ROS production. IL-10, the major anti-inflammatory interleukin, has been shown to suppress ROS release. It has been hypothesised that the method of suppression varies as we age. In younger people it was shown that IL-10 inhibited ROS production in response to IFN $\gamma$ stimulation, through interaction with the protein kinase A (PKA) pathway which switches to the p38 pathway towards middle age (Chaves et al., 2009). In the elderly IL-10 showed no suppressive effects on ROS release. Similar results were also obtained considering leukocytes from type II diabetic patients who showed that IL-10 had relinquished its typical ROS inhibitory properties in this disease state (Nogueira-Machado, 2003).

Although not regarded as a pro-inflammatory cytokine TGF $\beta$ has been implicated in directing the assembly of functional NADPH oxidase on the membrane of premonocytic cells (Basoni et al., 2006).

\section{Measuring ROS Production}

A number of techniques exist for monitoring and measuring cellular ROS which are typified by ROS causing excitation or a spectroscopic shift of one of a multitude of reporter molecules. This can then be quantified using luminometry, flow cytometry or microscopy. ROS reporting assays can be tailored to investigate the role of particular oxidative species in a cell response by using probes with specific interactions with target oxidants or by inclusion of scavenger molecules such as formate $(\mathrm{OH} \cdot)$, deferoxamine $\left(\mathrm{Fe}^{2+}\right)$, diethyldithiocarbamic acid (SOD inhibitor) and salicylhydroxamic acid (myeloperoxidase inhibitor) to ablate defined ROS or ROS precursors from the reaction milieu.

\section{Pholasin $^{\circledR}$}

The authors have used Pholasin ${ }^{\circledR}$, a luminescent protein, as a ROS probe with great success for quantifying the respiratory burst of leukocytes as a component of preclinical evaluation of implantable biomaterials. Pholasin ${ }^{\circledR}$ is a promiscuous ROS excitable photo-protein derived 
from the marine mollusc Pholas dactylus, which emits measurable photons in the presence of most intra and extra cellular derived ROS - including superoxide anion, hydroxyl radical and possibly ferryl radical as well as singlet oxygen and the non-radical oxidants: hypochlorous and hyprobromous acids and peroxynitrite. Therefore Pholasin ${ }^{\circledR}$ provides a sensitive measure of all cellular secreted ROS without species specific discrimination. Pholasin $^{\circledR}$ is not actively internalised into cells therefore is considered a specific measure of ROS released as a function of phagocyte degranulation (Knight et al., 1996; Knight, 1997; Muller et al., 1998; Reichl et al., 2000; Reichl et al., 2001; Glebska and Koppenol, 2005; Bryan et al., 2012a; Bryan et al., 2012b).

\section{Luminol}

Luminol (5-Amino-2,3-dihydro-1,4-phthalazinedione) is a synthetic molecule of which the ability to oxidise producing $\mathrm{N}_{2}$ and light emitting aminophthalate is widely exploited in molecular biology. Despite this, in the context of cellular ROS its interactions with phagocyte derived oxidants are poorly understood and the precise species which stimulate its excitation are debated. Reports vary as to the specificity of luminol for precise species. However, it is generally regarded that myeloperoxidase activity is crucial for luminol excitation by leukocytes suggesting a rate limiting role of hypohalous acids in its fluorescence emission. Whilst the influence of the MPO arm of the leukocyte ROS system on luminol is reasonably well agreed upon, studies often contradict one another with respect to the ability of additional ROS to excite this probe. Conflicting reports have hypothesised that luminol can also be excited by $\mathrm{H}_{2} \mathrm{O}_{2}, \mathrm{OH}^{-}, \mathrm{O}_{2}^{-}$, and $\mathrm{ONOO}^{-}$. Luminol has the ability to diffuse across cell membranes, which means that it reports both intra and extracellular ROS and can also be used microscopically to visually track ROS producing cells. Recently, luminol has also been used to track reactive ROS in vivo by means of delivery into the peritoneum and subsequent observation of ROS in response to subcutaneously delivered biomaterials using whole animal imaging of hairless mice (Vilim and Wilhelm, 1989; Samuni et al., 1991; Faulkner and Fridovich, 1993; Dahlgren and Karlsson, 1999; Myhre et al., 2003; Rinaldi et al., 2007; Liu et al., 2011).

\section{2,7-Dichlorodihydrofluorescein (DCFH)}

$\mathrm{DCFH}$ is oxidised in the presence of ROS to 2,7-dichlorofluorescein (DFH), a fluorescent compound which emits light at $520 \mathrm{~nm}$. A precursor molecule, DCFH diacetate, can traverse cell membranes readily and become de-acetylated into bioactive DCFH by intracellular esterases. This molecule is therefore suitable for monitoring of both intracellular and extracellular ROS. It is another promiscuous reporter molecule; excited by superoxide, hydroxyl, and peroxyl radicals in addition to reactive nitrogen species. Reports have also suggested that DFH-mediated fluorescence may be a product of enzymatic oxidation of DCFH by intracellular oxidases such as SOD and xanthine oxidase or interaction with haeme and haemoproteins, which is of paramount consideration when utilising this probe to monitor leukocyte ROS emission in a whole blood environment. Additionally, the succinimidyl ester of 2',7'-dichlorodihydrofluorescein diacetate is amine reactive and therefore can be conjugated to a number of substrates and proteins which has allowed study of material uptake by phagocytes and monitoring of ROS release occurring directly within the phagosome (Ohashi et al., 2002; Myhre et al., 2003; Gomes et al., 2005; Rinaldi et al., 2007; Tlili et al., 2011; Kalyanaraman et al., 2012).

\section{Lucigenin}

Lucigenin (10-Methyl-9-(10-methylacridin-10-ium-9yl)acridin-10-ium dinitrate) is another synthetic ROS probe; however, in contrast to luminol it is not membrane permeable. Lucigenin is typically considered to be specific to superoxide in extracellular fluids (Rathakrishnan and Tiku, 1993; Faulkner and Fridovich, 1993; Myhre et al., 2003).

\section{Cytochrome C}

The spectroscopic shift caused by the reduction of cytochrome c $\left(\right.$ cyt.Fe $\left.{ }^{3+}\right)$ can be used to quantify production of superoxide. Iron bound to cytochrome $\mathrm{C}$ becomes reduced $\left(\right.$ cyt. $\left.\mathrm{Fe}^{2+}\right)$ in the presence of this radical which causes a measurable absorbance maxima at $550 \mathrm{~nm}$ (Sanders et al., 1994; Hadjur and Jardon, 1995; Rinaldi et al., 2007).

\section{Electron spin resonance (ESR)}

ESR utilises a one of a family of 'spin trapping' molecules. In this technique, ROS binds to a synthetic molecule causing a measurable shift in the ESR of that molecule. The shift will vary as a function of the numerous different ROS species which could bind the reporter resulting in a series of potential molecular configurations. The result is a quantifiable ESR spectroscopic fingerprint simultaneously interrogating multiple radical species in a single assay. Typically, spin traps are nitrone or nitroso compounds. Nitrone compounds react with most cellular ROS however the nature of the physiochemical interaction between ROS and these reporters makes resolving the precursor radical species difficult. Nitroso compounds react with a more limited range of ROS, however their origins are easier to resolve. Spin trap molecules include

MNP (2-methyl-2-nitrosopropane), 3,5-dibromo-4nitrosobenzene sulfonic acid, DBNBS (3,5-dibromo-4nitrosobenzene sulfonic acid) and DMPO (5,5-dimethyl1-pyrroline N-oxide) (Sanders et al., 1994).

\section{ROS Considerations in Wound Healing and Biomaterials}

\section{Wound healing}

Wound healing is a complex and challenging cellular and biochemical event which requires the uniting of numerous cells to synergise and remodel the compromised tissues. Within a wound healing niche many cell types exist, whose signals to one another in both endocrine and paracrine fashions ensure a return to normal homeostasis of the damaged area. Wound healing involves an optimal combination of the constructive and destructive roles of 
cells and their associated ROS to remodel tissue in parallel to eradicating infectious organisms and non-self-material.

Leukocytes possess a vast number of systems to influence the healing of a tissue. Arguably, most researched are the interleukin family of proteins which are the major language with which cells in a healing wound converse. Interleukins have the ability to mediate leukocyte chemotaxis (IL-8), promote (IL-1, IL-6, IL-17, IL-23) and demote (IL-10) inflammation in addition to controlling the development and specificity of immunological memory (IL-2, IL-4, IL-15, IL-7). Additional protein signals are secreted by leukocytes and stroma into the wound healing milieu and play a pivotal role in driving appropriate cell populations within the tissue space, including TGF $\beta$, $\mathrm{TNF} \alpha, \mathrm{MCP}-1$ and IFN $\gamma$.

Further to their signalling roles, proteins secreted by leukocytes also have destructive properties. Typically, in the form of enzymes which possess the ability to degrade or reduce the integrity of bacterial extracellular matrices (perforin, defensins). This results in stasis, lysis or creates pores through which further leukocyte secreted compounds can enter and corrupt the intercellular husbandry of an infected cell to induce apoptosis (granzyme) or deplete extracellular fluids of vital trace minerals required for bacterial proliferation (lactoferrin) (Gutteridge et al., 1981; Okutomi et al., 1997; Nathan, 2006; Pham, 2008).

Similarly to proteins, ROS have the ability to act in both signalling and host defence capacities. Also similar to proteins such as matrix metalloproteinases, ROS have the potential to cause catastrophic damage to otherwise healthy tissue if left un-harnessed, therefore in the healing wound it is imperative that a balance is struck between the antimicrobial and tissue degenerative effects of phagocyte ROS. Indeed, it is this ROS-mediated tissue damage which plays a significant role in ageing and it has been hypothesised that the reliance on ROS during inflammation becomes greater throughout ageing (Khodr and Khalil, 2011).

ROS has also been implicated in causing fibrosis and scar formation. In a murine model of hepatic fibrosis, inclusion of the antioxidant $\alpha$-lipoic acid and an $\alpha$-lipoic acid derivative was shown to reduce fibrotic/cerotic effects by inhibiting ROS production and subsequent signalling by hepatic stellate cell activated by PDGF and TGF $\beta$ (Poli, 2000; Foo et al., 2011). ROS have also been implicated in pulmonary fibrosis, also involving the actions of TGF $\beta$ (Van der Vliet, 2008).

Chronic wounds are often characterised by the presence of excessive ROS or the absence of antioxidant ROS scavenger molecules such as vitamins E, C and glutathione. Interestingly, levels of wound antioxidants have been shown to decrease as we age, which corresponds to the delayed wound healing responses seen in the elderly. This suggests that reduced or delayed wound healing occurs as a consequence of lower concentrations of antioxidants allowing the wound ROS reaction to proceed unchecked, progressively compounding tissue damage (Schafer and Werner, 2008). This phenomenon has been shown in tissues as diverse as brain, demonstrating increased ROS synthesis in the absence of vitamin C (Kondo et al., 2008).
The use of antioxidants to enhance healing of chronic wounds has also been shown to be advantageous in conjunction with hyperbaric oxygen therapy. In this instance inclusion of $\alpha$-lipoic acid to restrict ROS mediated tissue damage was shown to enhance chronic wound healing whilst also decreasing the production of proinflammatory IL-6 (Alleva et al., 2005).

Similarly, in a mouse model of protein malnutrition (PM), known to delay wound healing the dietary inclusion of $\mathrm{N}$-acetylcysteine, an antioxidant which causes an increase in cellular glutathione was shown to enhance tissue repair. Furthermore, the study also used transgenic mice expressing varying amounts of SOD. Up-regulating this enzyme in PM was shown to also enhance wound healing however when animals were not fed a protein restricted diet this up-regulation impeded wound healing, suggesting a basal level of ROS is critical in appropriate and rapid tissue repair (Gordillo and Sen, 2003; Lim et al., 2006; Sen and Roy; 2008). Studies using knockout mice in which the gp9 $1^{\text {phox }}$ and $\mathrm{p} 47^{\text {phox }}$ subunits of NADPH were ablated concluded that in response to LPS, ROS actually play a key role in inflammatory resolution with knockout animals displaying greater production of inflammatory cytokines in response to LPS than wild-type equivalents (Zhang et al., 2009).

Despite the obvious cytotoxic effects of ROS, a basal level within the wound is advantageous outside of their role in sterilisation. For example, $\mathrm{H}_{2} \mathrm{O}_{2}$ is chemotactic to numerous cells involved in wound healing, particularly keratinocytes in which low levels of $\mathrm{H}_{2} \mathrm{O}_{2}$ promote cell migration and proliferation through activation of the ERK pathway (Loo et al., 2011). A low level of $\mathrm{H}_{2} \mathrm{O}_{2}(10 \mu \mathrm{M})$ has also been shown to be chemotactic to neutrophils (Klyubin et al., 1996). Interestingly, a further study utilised the antioxidant enzyme thioredoxin to inhibit neutrophil chemotaxis by LPS and also adhesion to epithelium, which would be reasonable to speculate was via a ROS-dependant mechanism (Nakamura et al., 2001).

In addition to phagocytes, stromal cells also have the ability to respond to ROS to orchestrate inflammation. A previous study showed that epithelial cells secreted the pro-inflammatory molecules ICAM1, TNF $\alpha, \mathrm{MCP}-1, \mathrm{IL}-8$ and IFN $\alpha$ in response to $\mathrm{H}_{2} \mathrm{O}_{2}$ in a dose dependant manner. It was hypothesised that this was due to $\mathrm{H}_{2} \mathrm{O}_{2}$ induction of NF- $\kappa$ B (De Oliveira Marques, 2007). Interestingly, this study also observed the synergistic expression of haeme oxygenase-1 (HO-1) which is anti-inflammatory, synthesising carbon monoxide which inhibits IL- $1 \beta$ and TNF $\alpha$ expression in macrophages.

Fibroblasts, whose proliferation, matrix deposition and potential differentiation play an important role in the sealing of a wound by secretion of collagens and other extracellular matrix proteins, which form a physical barrier to impede passage of microbes either into or through tissues of an organism, are also influenced by ROS. NADPH oxidase-derived ROS have been demonstrated to mediate the phenotype of fibroblasts by acting downstream of angiotensin II to stimulate differentiation into myofibroblasts through an influence on p38 and JNK signalling cascades. Indeed, ROS is implicated in 
several instances of fibrosis, diseases characterised as abnormalities in fibroblast number and phenotype in a diverse number of tissues from lung to heart (Shen et al., 2006; Lambeth, 2007).

\section{Biomaterials}

Intercellular ROS play a role downstream of extracellular growth factor receptor activation to induce transcriptional modification to coordinate several proliferative and remodelling effects, demonstrated studying the mitogenic effects of EGF on corneal epithelial cells (Huo et al., 2009). Highlighting the fine dose dependency of the beneficial and detrimental effects of ROS, the cytotoxic effects of 2-hydroxy-ethyl methacrylate (HEMA) and triethylene glycol dimethacrylate (TEGDMA) degradation products of resins, adhesives and cements used commonly in dental engineering have been contributed to an increase in intracellular ROS by oral epithelial cells (Chang et al., 2005; Demirci et al., 2007).

In response to excessive ROS within a wound, leukocytes and stromal cells possess a number of both intracellular, extracellular and membrane bound antioxidant systems to scavenge ROS before healthy tissue can become compromised. SOD may itself be considered a detoxification enzyme by dismutating the highly toxic superoxide radical into less destructive hydrogen peroxide. However, left undisposed of hydrogen peroxide has the potential to form the most reactive of all the radicals, $\mathrm{OH}$. Therefore, the enzymes glutathione peroxidase and catalase are produced, which both deconstruct hydrogen peroxide into water and oxygen. In addition to proteinaceous ROS control, fundamental antioxidant metabolites such as ascorbate, $\alpha$-tocopherol, NADPH, urate and lipoic acid all possess ROS-scavenging abilities. Indeed, it has been demonstrated that up-regulations occur in ROS scavenging enzymes during cutaneous wound healing, particularly at the wound edge possibly with the goal of protecting proliferative cells from the harmful oxidants contained within the compromised interstitial fluids (Steiling et al., 1999).

A previous study also implicated the ROS scavengers SOD and catalase as playing a major role in healing of periodontal wounds, whilst also implicating ROS in mediating the resorption profile of PLA implanted materials (Aliyev et al., 2004).

The importance of understanding the influence of biomaterials on wound healing ROS is widely acknowledged. Phagocytes interact directly and intimately with biomaterial surfaces and via receptor mediated activation through opsonisation of the material surface with endogenous protein or integrin remodelling. Foreign surfaces will almost inevitably lead to phagocyte ROS production. Indeed, previous research has demonstrated that the surface contact by the $\beta 2$ integrin chain (CD18) is a rate-limiting step in the release of phagocyte ROS stimulated by TNF $\alpha$ (Abram and Lowell, 2009).

The potential of a biomaterial to undergo phagocytosis greatly enhances its ability to stimulate cellular ROS as it is incorporated into the phagosome. Studies have demonstrated, using zinc nanoparticles, that macrophages produce more significant ROS in response to smaller particles (10-30 nm) which corresponds to an optimal size to phagocytose (Song et al., 2010).

Previous studies have demonstrated the ability of biomaterials to quench ROS release, demonstrating the intrinsic antioxidant capacity of several biomaterials which may be advantageous particularly in chronic wounds.

Previous work using hyaluronan based biomaterials has demonstrated their ability to quench superoxide released from polymorphonuclear phagocytes in vitro in a dose dependant manner. It was hypothesised in this study that the polymer forms a meshwork around individual cells making it difficult for ROS to escape into extracellular spaces (Moseley et al., 2003). Research has also suggested coenzyme Q10 (CoQ10), a naturally occurring quinone endogenous to most cells, as a biomaterial component due to its native role in oxidative stress protection. CoQ10 has been grafted onto PLGA microspheres which demonstrated an ability to quench ROS greater than CoQ10 alone and has been hypothesised for use in fields associated with ROS elevation (Swarnakar et al., 2011).

Metals and metallic compounds have also been highlighted as excellent candidate materials for managing and manipulating ROS. Platinum-ferritin substrates have been demonstrated to act in a manner analogous to catalase and peroxidase in ROS detoxification. The widely acknowledged biocompatibility of titanium has been hypothesised to be due to the ability of this metal to scavenge ROS onto its surface during titanium oxide formation in vivo (Taylor et al., 1996; Fan et al., 2011).

Additionally, studies have hypothesised fullerenes as biomaterial constituents due to their ability to scavenge ROS and protect primary cells from oxidative stress (Markovic and Trajkovic, 2008; Yin et al., 2009).

The ability of biological polymers to scavenge ROS has also been considered in the instance of wound dressings (Schonfelder et al., 2005). Research has shown that dressings synthesised from oxidised regenerated cellulose (ORC) and ORC:collagen co-polymers quench ROS more than collagen alone. However, collagen did demonstrate some ROS quenching capacity. A wound dressing with ROS scavenging capability would be particularly advantageous in the instance of chronic non-healing wounds, where ROS contribute massively to the nonhealing nature of the damaged tissue. ROS quenching is not an implied characteristics of a biopolymer though, chitosan and chitosan/soy copolymers have been demonstrated not to quench ROS produced by fMLP/PMA leukocyte induced activation, although these polymers were shown themselves not to exhibit any intrinsic ROS stimulating potential (Santos et al., 2007).

It may also be possible to manage and manipulate ROS in a biomaterial context by inhibition of the ROS synthesis pathway. It has been suggested that antibodies against ROS synthetic enzymes such as myeloperoxidase and components of NADPH oxidase may play a future role in eliminating the products of these enzymes from the inflammatory milieu by cross-linking and subsequent deactivation. Conversely, it may also be possible to include recombinant or purified ROS processing enzymes such as SOD and catalase and synthetic mimetics of these proteins as part of a material delivery strategy to control ROS 
damage during material integration (Cheung et al., 2008; Nishikawa et al. 2009).

The ROS stimulating capabilities of a material come not only from the material itself but also as a consequence of the material becoming coated with proteins the instant it contacts blood (Nygren et al., 2001). Often, particularly in the case of complement and immunoglobulins, these proteins have the capacity to stimulate ROS production. In response to this, much research is targeted on the production of anti-fouling surfaces which inhibit protein adhesion, or the generation of surfaces which include molecules such as nitroxide radical containing polymers, akin to those used for spin trap ROS characterisation which ablates ROS by conversion into a stable non radical product on the material surface (Yoshitomi et al., 2012). Similar techniques using nitroxide radicals grafted onto biopolymer nanoparticles has been suggested as therapeutic devices to control the inflammatory damage occurring during acute tissue injury, with a particular interest in renal damage (Yoshitomi et al., 2011).

\section{ROS and Cell Signalling}

Outside of their destructive role, ROS play a part in coordinating inflammation through their signalling capacity. The change in focal cellular Redox which accompanies ROS release is an important messenger system both inside and outside the cell. The molecular criteria of a successful signalling molecule suggest that it should be enzymatically generated and the signal should have the propensity to be ceased also by enzymatic degradation. This set of boundaries is fulfilled by several ROS including $\mathrm{NO}, \mathrm{O}_{2}^{-}$and $\mathrm{H}_{2} \mathrm{O}_{2}$. The destructive role of ROS is attributed to their deforming properties on biological polymers, which may also contribute to their signalling capacity allowing them to irreversibly modify proteins and transcription factors to influence cell fate and phenotype (Fialkow et al., 2007).

\section{Intracellular ROS Signalling}

The redox state which accompanies a change in intracellular ROS plays a pivotal role in translating the binding of extracellular receptors into functional transcription, this has been implied in multiple signalling cascades including MAPK/ERK, PKC and NF- $\kappa \mathrm{B}$ inducible kinase involving transcription factors such as NF- $\mathrm{BB}, \mathrm{AP}-1$ and NRf-2 which combined have the ability to mitigate a diverse range of inflammatory cellular outcomes (Gupta et al., 2011). ROS mediated activation of $\mathrm{NF}-\kappa \mathrm{B}$ alone may result in the production of MCP-1, IL-6, TNF $\alpha$ and IL- $1 \alpha / \beta$ (Millar et al., 2007; Naik and Dixit, 2011).

In cells, NF- $\kappa \mathrm{B}$ is repressed by its inhibitory molecule, $\mathrm{I} \kappa \mathrm{B}$. Phosphorylation of $\mathrm{I} \kappa \mathrm{B}$ by I $\mathrm{kb}$ kinase releases $\mathrm{NF}-\kappa \mathrm{B}$ allowing translocation to the cell nucleus and transcription of numerous NF- $\kappa \mathrm{B}$ mediated genes which in phagocytes includes several cytokines (IL-1, IL-6, IL-8, MIP-2), cytokine receptors, acute phase proteins, MHC and adhesion molecules rate-limiting in inflammation and wound healing (Clark and Valente, 2004; Abram and Lowell, 2009). This dissociation can occur as a result of an increase in intracellular $\mathrm{H}_{2} \mathrm{O}_{2}$ concentration which in monocytic cells stimulated with IL- $1 \beta$ has been shown to be a downstream product of NADPH oxidase activation.

$\mathrm{H}_{2} \mathrm{O}_{2}$ has been demonstrated to act as a second messenger during dendritic cell antigen presentation to T-lymphocytes. This process is complex and requires precise and intricate communication between the two inflammatory cells. Increase in dendritic cell ROS was shown to increase expression of CD86, directly corresponding to an increase in antigen presentation. However, inhibition of cellular redox signalling reduced secretion of IFN $\gamma$, IL-2 and IL-4 in the T-lymphocytes and IL- 6 and IL-12 in the antigen presenting cells. $\mathrm{H}_{2} \mathrm{O}_{2}$ has also been implicated as a second messenger in $\mathrm{F}_{\mathrm{c}}$ receptor mediated phagocytosis, possibly through ROS interaction with the tyrosine kinase syk.

NADPH oxidase produced ROS also act as second messengers to external proliferative signals, demonstrated using ceramide-1-phosphate. In this instance the signal transduction was elucidated to be via activation of the enzymes phospholipase $\mathrm{A}_{2}$ and PKC (Arana et al., 2012).

ROS also has the ability to positively feedback to NADPH oxidase to regulate further $\mathrm{O}_{2}^{-}$production. $\mathrm{H}_{2} \mathrm{O}_{2}$ has been shown to be a potent mediator of NADPH oxidase activation through a mechanism which involves an influx of $\mathrm{Ca}^{2+}$ via store-operated $\mathrm{Ca}^{2+}$ (SOC) channels, which are activated by emptying of intracellular $\mathrm{Ca}^{2+}$ stores as a consequence of the change in intracellular redox. Calcium influx activates the $\mathrm{Ca}^{2+}$ dependant PKC which phosphorylates and activates $\mathrm{p} 47^{\text {phox }}$ (Jamali et al., 2010). Contrary to $\mathrm{H}_{2} \mathrm{O}_{2}$ feedback, $\mathrm{NO}$ has been shown to decrease ROS production by inhibiting NADPH oxidase activity through a mechanism which involves deactivation of PKC, demonstrating two feedback loops targetting the same kinase with totally opposing cellular consequences (Klink et al., 2009).

Intracellular phagocyte ROS signalling events also directly influence the fate of alternative inflammatory cells. Intracellular $\mathrm{H}_{2} \mathrm{O}_{2}$ has been demonstrated to decrease transcription of the IL-12, a potent mediator of $\mathrm{T}_{\mathrm{h}} 1 \mathrm{~T}$ cell polarisation via inhibiting translocation of its transcription factor c-rel to the cell nucleus (Kahn et al., 2006).

During inflammation the intracellular ROS signalling by non-haematopoietic cells also plays its part. In endothelial cells, omnipresent in vasculature, increase in intracellular ROS causes a release of stored $\mathrm{Ca}^{2+}$ from the endoplasmic reticulum into the cytosol. This activates $\mathrm{Ca}^{2+}$ dependent MAPK signalling and extracellular P-selectin expression, which causes neutrophil cells to adhere to endothelium (Millar et al., Phan and Tibbles, 2007). $\mathrm{H}_{2} \mathrm{O}_{2}$ has also been demonstrated to up-regulate intercellular adhesion molecule (ICAM) expression in endothelial cells, which plays an important role in leukocyte transmigration and extravasation during inflammation (Hubbard and Rothlein, 2000).

In addition to $\mathrm{H}_{2} \mathrm{O}_{2}$ and the well-documented signalling roles of RNS, despite its short lived nature $\mathrm{O}_{2}^{-}$has also been demonstrated to have a signalling capacity in addition to its disinfectant properties. $\mathrm{O}_{2}^{-}$- directly stimulates $\mathrm{PKC}$ activity through interaction through liberation of zinc from its zinc finger region. PKC activation has the propensity 
to mediate multiple downstream cellular events including proliferation, transcription and differentiation (Knapp and Klann, 2000).

\section{Extracellular ROS signalling}

As stated previously, ROS are ideal signalling molecules due to the intricacy and control with which they can be synthesised and degraded. Coupled with this, the fact that several ROS - particularly $\mathrm{H}_{2} \mathrm{O}_{2}$ - are membrane permeable, make them excellent candidate paracrine signalling molecules that could influence multiple other haematopoietic and non-haematopoietic cells within the inflammatory milieu.

Exogenous oxidants have been shown to increase the rate of $\mathrm{F}_{\mathrm{c}} \mathrm{R}$ mediated phagocytosis by professional phagocytes. This was a consequence of $\mathrm{H}_{2} \mathrm{O}_{2}$ amplifying phosphorylation of intracellular F R ITAM motifs. The downstream signalling associated with $\mathrm{F} R$ stimulation involves activation of the transcription factor syk, the rate of which was increased in $\mathrm{H}_{2} \mathrm{O}_{2}$ treated leukocytes, confirming the downstream functionality of ROS enhanced $\mathrm{F}_{\mathrm{c}} \mathrm{R}$ efficiency (Pricop et al., 1999).

Myeloid cell ROS has been shown to directly influence the role of the adaptive arm of the immune system in inflammation through NADPH oxidase produced ROS. Macrophages can be categorised into two classes based on their inflammatory (M1) or anti-inflammatory (M2) cytokine release profile. M1 macrophages interact with aggressive $\mathrm{T}_{\mathrm{h}} 1 \mathrm{CD} 4 \mathrm{~T}$ lymphocytes which maintain the inflammatory response in an acute phase. M2 macrophages cross-talk with $\mathrm{T}_{\mathrm{h}} 2 \mathrm{CD} 4 \mathrm{~T}$-lymphocytes that drive inflammation towards a humeral phase. Studies have demonstrated that ROS secreted from M2 anti-inflammatory macrophages polarise the CD4 T-lymphocyte subset towards a $\mathrm{T}_{\text {reg }}$ phenotype in vitro. $\mathrm{T}_{\text {reg }}$ cells are actively involved in repressing the inflammatory response, therefore utilising a classically destructive group of molecules as an inflammatory repressor via their paracrine activation of anti-inflammatory cells (Kraaij et al., 2010). The molecular mechanism for this polarisation is undefined, although it has been postulated that this may be a result of interaction of ROS with membrane bound TGF $\beta$ on the lymphocytes.

Additional studies have also concluded an endocrine effect of ROS on lymphocytes. Incubating mixed populations of T-lymphocytes with granulocytes resulted in a decrease of IFN $\gamma$ secretion from the T-cell population. It was concluded that this phenomenon was dose dependant on $\mathrm{H}_{2} \mathrm{O}_{2}$. In this study, $\mathrm{H}_{2} \mathrm{O}_{2}$ was shown to suppress the pro-inflammatory nature of T-cells by additionally to IFN $\gamma$ also repressing TNF $\alpha$, IL-2 and IL-4 production. This was implied as a potential mechanism for the reduction in T-cell response observed towards tumours in advanced cancer patients (Schmielau and Finn, 2001). Reduction of T-cell cytotoxic potency by $\mathrm{H}_{2} \mathrm{O}_{2}$ has also been contributed to its ability to influence the TCR, reducing the expression of

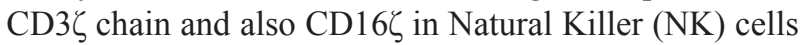
(Kono et al., 1996; Kumar and Sharma, 2010).

Apoptosis, unlike necrosis is an anti-inflammatory event critical in the resolution of inflammation. During this process cells undergo programmed death without elution of their cytotoxic intracellular compartments into the inflammatory milieu. Further anti-inflammatory ROS roles may be implicated in the ability of exogenous $\mathrm{NO}$ and $\mathrm{ONOO}^{-}$to cause neutrophil apoptosis. Although the apoptotic influence of NOS on phagocytes is well known, contrasting reports exist over the finer points of the phenomenon, which numerous dose dependant relationships suggest for windows in which NOS exhibit anti- rather than pro-apoptotic effects and, additionally, these observations may vary as a function of species (Ward et al., 2000a; Taylor et al., 2003).

Although yet to be demonstrated in a mammalian model, zebra fish studies have elegantly demonstrated a chemotactic role of $\mathrm{H}_{2} \mathrm{O}_{2}$ in recruiting phagocytes to wounded tissue. The $\mathrm{H}_{2} \mathrm{O}_{2}$ released from damaged tissue termed the 'wound burst' may play a role in recruiting the first wave of inflammatory cells to the wound. Phagocytes have been shown to chemotax up $\mathrm{H}_{2} \mathrm{O}_{2}$ gradients and a redox sensitive kinase; Lyn of the SFC kinase family has been implicated in the process. However, the precise mechanism by which activation of this kinase translates to cellular directional motility is yet to be defined (Yoo and Huttenlocher, 2009; Yoo et al., 2011).

Exogenous $\mathrm{H}_{2} \mathrm{O}_{2}$ has also been demonstrated to stimulate dendritic cell maturation from immature precursor cells. This was characterised by an increase in molecules associated with T-cell activation (HLA-DR, HLA-DQ, CD86, CD40) and a decrease in molecules associated with antigen capture (CD32) (Rutault et al., 1999). $\mathrm{H}_{2} \mathrm{O}_{2}$ stimulated DCs also demonstrated a greater capacity to promote T-cell proliferation during antigen presentation (Matsue et al., 2003).

\section{Conclusion}

Leukocytes are pivotal in orchestrating debridement, disinfection ultimate repair of compromised tissue. In order to achieve this, leukocytes possess an exquisite array of non-specific signalling and defensive molecules capable of undertaking constructive and destructive roles during wound healing. Crucially, leukocytes have the ability to rapidly and precisely produce a number of ROS which are incredibly cytotoxic molecules with potential to cause catastrophic damage to healthy tissue, whilst ensuring sterilisation of infected and damaged tissues. ROS also play a critical role in signalling both inside and outside of the cell. Indeed, generation of biomaterial surfaces with the ability to manage the ROS response within a healing tissue and maintain this potentially cytotoxic cellular process within a constructive window presents an extremely tantalising future prospect in medical device design. This level of coordination within a healing tissue by a material will provide a powerful antimicrobial effect during infiltration of host cells; accelerate the degradation of dead or dying cells and increasing the turnover and integration of healing stromal tissues with minimal fibrosis, scar formation and loss of mechanical strength.

Future research required in this area will involve characterisation and quantification of the species and amounts of ROS involved in normal wound healing. This 
will drive fabrication of biomaterials into an exciting generation of devices which ensure that ROS levels remain within a window of normalcy to reduce the consequences of ROS exacerbation, particularly in chronic non-healing wounds.

Future understanding of ROS in wound healing will also be heightened by the stem cell field, which is currently producing fascinating data suggesting that adult stem cells are exquisitely sensitive to changes in tissue redox with the potential to greatly alter their viability, plasticity and lineage commitment (Jang and Sharkis, 2007; Kim et al., 2007; Mouche et al., 2007; Carriere et al., 2009; Valle-Prieta and Conget, 2010; Kanda et al., 2011; Kim et al., 2011; Daly et al., 2012). Therefore, we must ensure that the biomaterials and stem cell communities unite to make one another acutely aware of the impact of material modifications of wound site ROS in the differentiation and proliferation of stem cells during tissue repair.

\section{References}

Abram CL, Lowell CA (2009) The ins and outs of leukocyte integrin signalling. Ann Rev Immunol 27: 339362.

Afonso V, Champy R, Mitrovic D, Collin P, Lomri A (2007) Reactive oxygen species and super oxide dismutases: Role in joint diseases. Joint Bone Spine 74: 324-329.

Aliyev E, Sakallioglu U, Eren Z, Acikgoz G (2004) The effect of polylactide membranes on the levels of reactive oxygen species on peridontal flaps during wound healing. Biomaterials 25: 4633-4637.

Alleva R, Nasole E, Di Donato F, Borghi B, Neuzil J, Tomasetti M (2005) alpha-lipoic acid supplementation inhibits oxidative damage, accelerating chronic wound healing in patients undergoing hyperbaric oxygen therapy. Biochem Biophys Res Commun 333: 404-410.

Anderson JM, Rodriguez A, Chang DT (2008) Foreign body response to biomaterials. Semin Immunol 20: 86-100.

Arana L, Gangoiti P, Ouro A, Rivera IG, Ordonez M, Trueba M, Lankalapalli RS, Bittaman R, Gomez-Munoz A (2012) Generation of reactive oxygen species (ROS) is a key factor for stimulation of macrophage proliferation by ceramide-1-phosphate. Exp Cell Res 318: 350-360.

Babensee JE, Anderson JM, McIntire MV, Mikos AG (1998) Host response to tissue engineered devices. Adv Drug Deliv Rev 33: 111-139.

Basoni C, Reuzeau E, Croft D, Genot E, Kramer IM (2006) CD44 and TGF $\beta 1$ synergise to induce expression of a functional NADPH oxidase in promyelocytic cell. Biochem Biophys Res Commun 343: 609-616.

Bose M, Farina P (1995) Proinflammatory cytokines can significantly induce human mononuclear phagocytes to produce nitric oxide by a cell maturation-dependant process. Immunol Lett 48: 59-64.

Bokoch GM, Zhao T (2006) Regulation of the phagocyte NADPH oxidase by Rac GTPase. Antioxid Redox Signal 8: 1533-1548.
Brechard S, Bueb JF, Tschirhart EJ (2008) Interleukin 8 primes oxidative burst in neutrophil like HL-60 through changes in cytosolic calcium. Cell Calcium 37: 531-540.

Brown DI, Griendling KK (2009) Nox proteins in signal transduction. Free Radic Biol Med 47: 1239-1253.

Bryan N, Ashwin H, Smart N, Bayon Y, Scarborough N, Hunt JA (2012a) The innate oxygen dependent immune pathway is a sensitive parameter to predict the performance of biological graft materials. Biomaterials 33: 6380-6392.

Bryan N, Smart NJ, Bayon Y Hunt JA (2012b) In vitro activation and degranulation of human acute inflammatory cells in response to direct contact with synthetic hernia repair meshes. Clin Biochem45: 672-676.

Buonocore G, Perrone S, Tatarrano ML (2010) Oxygen toxicity: chemistry and biology of reactive oxygen species. Semin Fetal Neonat Med 15: 186-190.

Carriere A, Ebrahimian TG, Dehez S, Auge N, Joffre C, Andre M, Arnal S, Duriez M, Barreau C, Arnaud E, Fernandez Y, Planat-Bernard V, Lévy B, Pénicaud L, Silvestre JS, Casteilla L (2009) Preconditioning by mitochondrial reactive oxygen species improves the proangiogenic potential of adipose-derived cells-based therapy. Artherioscler Thromb Vasc Biol 29: 1093-1099.

Chang HH, Guo MK, Kasten FH, Chang MC, Huang GF, Wang YL, Wang RS, Jeng JH (2005) Stimulation of glutathione depletion, ROS production and cell cycle arrest of dental pulp cells and gingival epithelial cells by HEMA. Biomaterials 26: 745-753.

Chaves MM, Costa DC, de Oliviera BF, Rocha MI, Nogueira-Machado JA (2009) Role PKA and p38 MAPK on ROS in neutrophil age related: Lack of IL-10 effect in older subjects. Mech Ageing Dev 130: 588-591.

Cheung CY, McCartney SJ, Anseth KS (2008) Synthesis of polymerizable superoxide dismutatse mimetics to reduce reactive oxygen species damage in transplanted biomedical devices. Adv Funct Mater 18: 3119-3126.

Clark RA Valente AJ (2004) Nuclear factor kappa B activation by NADPH oxidases. Mech Ageing Dev 125: 799-810.

Cooper AM, Segal BH, Frank AA, Holland SM, Orme IM (2000) Transient loss of resistance to pulmonary tuberculosis in p47 $7^{\text {phox-/- }}$ mice. Infect Immun 68: 1231-1234.

Dahlgren C, Karlsson A (1999) Respiratory burst in human neutrophils. J Immunol Meth 232: 3-14.

Daly KA, Liu S, Agrawal V, Brown BN, Johnson SA, Medberry CJ, Badylak SF (2012) Damage associated molecular patterns within xenogeneic biologic scaffolds and their effects on host remodelling. Biomaterials 33: 91-101.

Defranco DL, Locksley RM, Robertson M (2007) The Toll-like receptor family of innate immune receptors. In: Immunity: the Immune Response in Infectious and Inflammatory Diseases. Oxford University Press, Oxford, pp 74-75.

De Haan JB, Bladier C, Lofti-Miri M, Taylor J, Huchinson P, Crack PJ, Hertzog P, Kola I (2004) Fibroblasts derived from Gpx1 knockout mice display senescent-like features and are susceptible to $\mathrm{H}_{2} \mathrm{O}_{2}$ mediated cell death. Free Radic Biol Med 36: 53-64. 
Demirci M, Hiller KA, Bosl C, Galler K, Schmalz G, Schweikl H (2008) The induction of oxidative stress, cytotoxicity, and genotoxicity by dental adhesives. Dent Mater 24: 632-371.

De Oliveira Marques V, Cyrne L, Marinho HS, Antunes $\mathrm{F}$ (2007) A quanititative study of NF- $\kappa$ B activation by $\mathrm{H}_{2} \mathrm{O}_{2}$ : Relevance in inflammation and synergy with TNFa. J Immunol 178: 3893-3902.

Devereux DF, O’Connell SM, Liesch JB, Weinstein M, Robertson FM (1990) Induction of leukocyte activation by meshes surgically implanted in the peritoneal cavity. Am J Surg 162: 243-246

Dewas C, Dang PMC, Gougerot-Pocidalo MA, El-Benna J (2003) TNF $\alpha$ induces phosphyorylation of p47phox in human neutrophils: partial phosphyorylation of $\mathrm{p} 47^{\text {phox }}$ is a common event of priming of human neutrophils by TNF $\alpha$ and granulocyte macrophage colony stimulating factor. J Immunol 171: 4392-4398.

Diebold BA Bokoch GM (2001) Molecular basis for Rac2 regulation of phagocyte NADPH oxidase. Nat Immunol 2: 211-215.

Di Virgilio F, Chiozzi P, Ferrari D, Falzoni S, Sans JM, Morelli A, Torboli M, Bolognesi G, Baricordi R (2001) Nucleotide receptors: an emerging family of regulatory molecules in blood cells. Blood 97: 587-600.

Ehrengruber MU., Geiser T, Derenleau DA (1994) Activation of human neutrophils by $\mathrm{C} 3 \mathrm{a}$ and $\mathrm{C} 5 \mathrm{~A}$ Comparison on the effects of shape changes, chemotaxis, secretion and respiratory burst. FEBS Lett 346: 181-184.

Emming SA, Hammerschmidt M, Krieg T, Roers A (2009) Interrelation of immunity and tissue repair or regeneration. Semin Cell Developm Biol 20: 517-527.

Fan J, Yin JJ, Ning B, Wu X, Yu H, Ferrari M, Anderson GJ, Wei J, Zhao Y, Nie G (2011) Direct evidence for catalase and peroxidase activities of ferritin-platinum nanoparticles. Biomaterials 32: 1611-1618.

Fattman CL, Schaefer LM, Oury TD (2003) Extracellular superoxide dismutatse in biology and medicine. Free Radic Biol Med 35: 236-256.

Faulkner K, Fridovich I (1993) Luminol and Lucigenin as detectors for $\mathrm{O}_{2}-$. Free Radic Biol Med 15: 447-451.

Ferguson LR, Bronzetti G, De Flora S (2005) Mechanistic approaches to chemoprevention of mutation and cancer. Mutat Res 591: 3-7.

Fialkow L, Wang Y, Downey GP (2007) Reactive oxygen and nitrogen species as signalling molecules regulating neutrophil function. Free Radic Biol Med 42: 153-164.

Franz S, Rammelt S, Scharnweber D, Simon JC (2011) Immune response to implants - A review for the implications for design of immunomodulatory biomaterials. Biomaterials 32: 6692-6709.

Foo NP, Lin SH, Lee YH, Wu MJ, Wang YJ (2011) $\alpha$-lipoic acid inhibits liver fibrosis through attenuation of ROS-triggered signalling in hepatic stellate cells activated by PDGF and TGF- $\beta$. Toxicology 282: 39-46.

Glebska J Koppenol WH (2005) Chemiluminescence of Pholasin ${ }^{\circledR}$ caused by peroxynitrite. Free Radicals Biol Med 38: 1014-1022.
Gomes A, Fernandes E, Lima JLFC (2005) Fluorescence probes used for detection of reactive oxygen species. $\mathrm{J}$ Biochem Biophys Meth 65: 45-80.

Gordillo GM, Sen CK (2003) Revisiting the essential role of oxygen in wound healing. Am J Surg 186: 259-263.

Gozal E, Forman HJ, Torres M (2001) ADP stimulated the respiratory burst without activation of ERK and AKT in rat alveolar macrophages. Free Radic Biol Med 31: 679-687.

Groemping Y, Lapouge K, Smerdon SJ, Rittinger K (2003) Molecular basis of phosphorylation-induced activation of the NADPH oxidase. Cell 113: 343-355.

Gupta S, Dhiman M, Wen JJ, Garg NJ (2011) ROS signalling of inflammatory cytokines during Trypanosome cruzi infection. Adv Parasitol 76: 153-170.

Gutteridge JMC, Paterson SK, Segal AW, Halliwell B (1981) Inhibition of lipid peroxidation by the iron-binding protein lactoferrin. Biochem J 199: 259-261.

Hadjur C. Jardon P (1995) Quantitative analysis of superoxide anion radicals photosensitized by hypericin in a model membrane using the cytochrome c reduction method. J Photochem Photobiol B 29: 147-156.

Henderson LM, Chappell JB (1996) NADPH oxidase of neutrophils. Biochim Biophys Acta 1273: 87-107.

Herre J, Gordon S, Brown DB (2004) Dectin-1 and its role in recognition of beta-glucans by macrophages. Mol Immunol 40: 869-876.

Higurashi S, Machino Y, Suzuki A, Suzuki M, Kohraki J, Masuho Y (2012) Both the Fab and Fc domains of IgG are essential for ROS emission from TNF-alpha-primed neutrophils by IVIG. Biochem Biophys Res Commun 417: 794-799.

Hubbard AK. Rothlein R (2000) Intercellular adhesion molecule-1 (ICAM-1) expression and cell signalling cascades. Free Radic Biol Med 28: 13-79-1386

Huo Y, Qiu WY, Pan Q, Yao YF, Xing K, Lou MF (2009) Reactive oxygen species (ROS) are essential mediators in epidermal growth factor (EGF)-stimulated corneal epithelial cell proliferation, adhesion, migration and wound healing. Exp Eye Res 89: 876-886.

Indik ZK, Park JG, Hunter S, Schreiber AD (1995) The molecular dissection of $\mathrm{Fc}$ gamma receptor mediated phagocytosis. Blood 86: 4389-4399.

Jamali AE, Valente AJ, Clark RA (2010) Regulation of phagocyte NADPH oxidase by hydrogen peroxide through $\mathrm{Ca}^{2+} / \mathrm{c}-\mathrm{Abl}$ signalling pathway. Free Radic Biol Med 48: 798-810.

Jang YY, Sharkis SJ (2007) A low level of reactive oxygen species selects for primitive hematopoetic stem cells that may reside in the low oxygenic niche. Blood 110: 3056-3063.

Jann NJ, Schmaler M, Ferracin F, Landmann R (2011) TLR2 enhances NADPH oxidase activity and killing of Staphlococcus aureus by PMN. Immunol Lett 135: 17-32.

Janssen-Heininger Y, Ckless K, Reynaert N, Van der Vliet A (2005) SOD inactivation in asthma: bad news or NO news? Am J Pathol 166: 649-652.

Jeannin P, Jaillon S, Delneste Y (2008) Pattern recognition receptors in the immune response against dying cells. Curr Opin Immunol 20: 530-537. 
Johnson F, Giulivi C (2005) Superoxide dismutases and their impact upon human health. Mol Aspects Med 26: $340-352$.

Kader KN, Coyle CH (2007) Reactive oxygen and nitrogen species: Implications for cardiovascular device engineering. J Biomed Mater Res B: Appl Biomater 83: 138-144.

Kahn N, Rahim SS, Boddupali CS, Ghousunissa S, Padma S, Pathak N, Thiagarajan D, Hasnain SE, Mukhopadhyay S (2006) Hydrogen peroxide inhibits IL-12 p40 induction in macrophages by inhibiting c-rel translocation to the nucleus through activation of calmodulin protein. Blood 107: 1513-1520.

Kalyanaraman B, Darley-Usmar V. Davies JJA, Dennery PA, Foreman HJ, Grisham MB, Mann GE, Moore K, Roberts LJ, Ischiropoulos H (2012) Measuring reactive oxygen and nitrogen species with fluorescent probes: challenges and limitations. Free Radical Biol Med 52: 1-6.

Kanda Y, Hinata T, Kang SW, Watenabe Y (2011) Reactive oxygen species mediate adipocyte differentiation in mesenchymal stem cells. Life Sci 89: 250-258.Kanneganti TD, Lamkafani M, Nunez G (2007) Intracellular Nod-like receptors in host defense and disease. Immunity 27: 549559.

Kasahara E, Sekiyama A, Hori M, Hara K, Takahashi N, Konishi M, Sato EF, Matsumoto S, Okamura H, Inoue M (2011) Mitochondrial density contributes to the innate response of macrophages to lipopolysaccharide via the MAPK pathway. FEBS Lett 585: 2263-2268.

Kawai T, Akira S (2007) TLR signalling. Semin Immunol 19: 24-32.

Khodr B, Khalil Z (2001) Modulation of inflammation by reactive oxygen species: Implications for ageing and tissue repair. Free Radic Biol Med 30: 1-8.

Kim JH, Park SH, Park SG, Choi JS, Xia Y, Sung JH (2011) The pivotal role of reactive oxygen species generation in the hypoxia induced stimulation of adipose derived stem cells. Stem Cells Dev 20: 1753-1761.

Kim JS, Kim EJ, Kim HJ, Yang JY, Hwang GS, Kim CW (2007) Proteomic and metabolomic analysis of $\mathrm{H}_{2} \mathrm{O}_{2}$ induced premature senescent human mesenchymal stem cells. Exp Gerontol 46: 500-510.

Klegeris A McGeer PL (1994) Inhibition of respiratory burst in macrophages by complement receptor blockade. Eur J Pharmacol 260: 273-277.Klink M, Jasrzembska K,

Bednarska K, Banasik M, Sulowska Z (2009) Effect of nitric oxide donors on NADPH oxidase signalling pathway in human neutrophils in vitro. Immunobiology 214: 692702.

Klyubin IV, Kirpichnikova KM, Gamaley IA (1996) Hydrogen peroxide-induced chemotaxis of mouse peritoneal neutrophils. Eur J Cell Biol 70: 347-351.

Knapp LT, Klann E (2000) Superoxide-induced stimulation of protein kinase $\mathrm{C}$ via thiol modification and modulation of zinc content. J Biol Chem 275: 2413624145.

Knight J (1997) The piddock and the Immunologist. Immunol News 4[1]: 26-31.

Knight J, McCafferty A, Noon E, Bell A(1996). Indirect evidence to support the production of hydroxyl and/or ferryl radicals at sites of inflammation. Br J Rheumatol 35 [Abstr suppl 2].

Kondo Y, Sasaki T, Sato Y, Amano A, Aizawa S, Iwama M, Handa S, Shimada M, Fukuda M, Akita M, Lee J, Jeong KS, Maruyama M, Ishigami A (2008) Vitamin C depletion increases superoxide generation in brains of SMP30/GNL knockout mice. Biochem Biophys Res Commun 377: 291296.

Kono K, Salazar-Onfray F, Petersson M, Hansson J, Masucci G, Wasserman K, Nakazawa T, Anderson P, Kiessling R (1996) Hydrogen peroxide secreted by tumor derived macrophages down regulates signal transuding zeta molecules and inhibits tumor specific $\mathrm{T}$ cell and natural killer cell mediated toxicity. Eur J Immunol 26: 1308-1313.

Kraaij MD, Savage NDL, Van der Kooij SW, Koekkoek K, Wang J, Van der Berg M, Ottenhoff THM, Kuijpers TW, Holmdahl R, Van Kooten C, Gelderman KA (2010) Induction of regulatory $\mathrm{T}$ cells by macrophages is dependant on production of reactive oxygen species. Proc Natl Acad Sci USA 41: 17686-17691.

Kumagai Y, Akira S. (2010) Identification and functions of pattern-recognition receptors. J Allergy Clin Immunol125: 985-992.

Kumar V, Sharma A (2010) Neutrophils: Cinderella of innate immune system. Internat Immunopharmacol 10: 1325-1334.

Lam GY, Huang J, Brumell JH (2010) The many roles of NOX2 NADPH oxidase-derived ROS in immunity. Semin Immunopathol 32: 415-430.

Lambeth DJ (2007) Nox enzymes, ROS, and chronic disease: an example of antagonistic pleiotropy. Free Radic Biol Med 43: 332-347.

Lambeth JD, Kawahara T, Diebold B (2007) Regulation of nox and duox enzymatic activity and expression. Free Radical Biol Med 43: 319-331.

Leslie RGQ (2001) Complement receptors. In: Encyclopaedia of Life Sciences. Wiley, Chichester, pp 1 $-9$.

Lim Y, Levy MA, Bray TM (2006) Dietary supplementation of $\mathrm{N}$-acetylcysteine enhances early inflammatory responses during cutaneous wound healing in protein malnourished mice. J Nutr Biochem 17: 328-336.

Limon-Pacheco J, Gosebatt ME (2009) The role of antioxidants and antioxidant-related enzymes in protective responses to environmentally induced oxidative stress. Mutat Res 674: 137-147.

Liu WF, Ma M, Bratlie KM, Dang TT, Langer R, Anderson DG (2011) Real-time in vivo detection of biomaterial-induced reactive oxygen species. Biomaterials 32: 1796-1801.

Loo AEK, Ho R, Halliwell B (2011) Mechanism of hydrogen peroxide-induced keratinocytes migration in a scratch-wound model. Free Radic Biol Med 51: 884-892.

Maher J, Yamamoto M (2010) The rise of antioxidant signalling - the evolution and hormetic actions of Nrf2. Toxicol Appl Pharmacol 244: 4-15.

Markovic Z, Trajkovic V (2008) Biomedical potential of the reactive oxygen species generation and quenching by fullerenes $\left(\mathrm{C}_{60}\right)$. Biomaterials 29: 3561-3573.

Matsue H, Edelbaum D, Shalhevet D, Mizumoto N, Yang C, Mummert ME, Oeda J, Masayasu H, Takashima A 
(2003) Generation and function of reactive oxygen species in dendritic cells during antigen presentation. J Immunol 171: 3010-3018.

McGreal EP, Miller JL, Gordon S (2005) Ligand recognition by antigen-presenting c-type lectin receptors. Curr Opin Immunol 17: 18-24.

Millar TM, Phan V, Tibbles LA (2007) ROS generation in endothelial hypoxia and reoxygenation stimulates MAP kinase signalling and kinase- dependant neutrophil recruitment. Free Radic Biol Med 42: 1165-1177.

Mizuki K, Takeya R, Kuribayashi F, Nobuhisa I, Kohda D, Nunoi H, Takeshige K, Sumimoto H (2005) A region $\mathrm{C}$-terminal to the proline-rich core of $\mathrm{p} 47^{\text {phox }}$ regulates activation of the phagocyte NADPH oxidase by interacting with the C-terminal SH3 domain of $\mathrm{p} 67^{\text {phox }}$. Arch Biochem Biophys 444: 185-194.

Moseley R, Walker M, Waddington RJ, Chen WYJ (2003) Comparison of the antioxidant properties of wound dressing materials-carboxymethylcellulose, hyaluronan bezyl ester and hyaluronan, towards polymorphonuclear leukocyte-derived reactive oxygen species. Biomaterials 24: 1549-1557.

Mouche S, Mkaddem SB, Wang W, Katic M, Tseng YH, Carnesecchi S (2007) Reduced expression of the NADPH oxidase NOX4 is a hallmark of adipocyte differentiation. Biochim Biophys Acta 1773: 1015-1027.

Muller T, Davies EV, Campbell AK (1989) Pholasin ${ }^{\circledR}$ chemiluminescence detects mostly superoxide anion released from activated human neutrophils. J Bioluminesc Chemiluminesc 3: 105-113.

Myhre O, Andersen JM, Aarnes H, Fonnum F (2003) Evaluation of the probes 2',7'-dicloroflourescin diacetate, luminol and Lucigenin as indicators of reactive species formation. Biochem Pharmacol 65: 1757-1782.

Naik E, Dixit VM (2011) Mitochondrial reactive oxygen species drive proinflammatory cytokine production. J Exp Med 31: 519-533.

Nakamura H, Herzenberg LA, Bai J, Araya S, Kondo N, Nishinaka Y, Herzenberg LA, Yodoi J (2001) Circulating thioredoxin suppresses lipopolysaccharide-induced neutrophil chemotaxis. Proc Natl Acad Sci USA 98: 15143 15148.

Nathan C (2006) Neutrophils and immunity challenges and opportunities. Nat Rev Immunol 7: 173-182.

Nathan C, Shiloh MU (2000) Reactive oxygen and nitrogen intermediates in the relationship between mammalian hosts and microbial pathogens. Proc Natl Acad Sci USA 97: 8841-8848.

Nimmerjahn F, Ravetch JV (2008) Fcgamma receptors as regulators of immune responses. Nature 8: 34-47.

Nishikawa M, Hashida M, Takaura Y (2009) Catalase delivery for inhibiting ROS-mediated tissue injury and tumor metastasis. Adv Drug Deliv Rev 61: 319-326.

Nogueira-Machado JA, Lima e Silva FC, Medina LO, Costa DC, Chaves MM (2003) Modulation of reactive oxygen species (ROS) generation mediated by cyclic AMP-elevating agents or interleukin-10 in granulocytes from type 2 diabetic patients (NIDDM): A PKA-dependant phenomenon. Diabetes Metab 29: 533-537.

Nygren H, Broberg M, Eriksson C, Sahlin H, Yahyapour N (2001) The respiratory burst response of surface-adhering leukocytes. A key to tissue engineering. Colloids Surf B Biointerfaces 22: 87-97.

Ohashi T, Mizutani A, Murakami A, Kojo S, Ishii T, Taketani S (2002) Rapid oxidation of dihydrochloroflourescin with heme and hemoproteins: formation of the fluorescin is independent of the generation of reactive oxygen species. FEBS Lett 511: 21-27.

Okutomi T, Abe S, Tansho S, Wakabayashi H, Kawase K, Yamaguchi H (1997) Augmented inhibition of growth of Candida albicans by neutrophils in the presence of lactoferrin. FEMS Immunol Med Microbiol 18: 105-112.

Osario F, Reis e Sousa C (2011) Myeloid C-type lectin receptors in pathogen recognition and host defense. Immunity 34: 651-664.

Park JE, Barbul A (2004) Understanding the role of immune regulation in wound healing. Am J Surg 187: $11 \mathrm{~S}-16 \mathrm{~S}$.

Pham CT (2008) Neutrophil serine proteases fine-tune the inflammatory response. Int J Biochem Cell Biol 40: 1317-1333.

Poli G (2000) Pathogenesis of liver fibrosis: role of oxidative stress. Mol Aspects Med 21: 49-98.

Philpott DJ, Girardin SE (2010) Nod-like receptors: sentinels at host membranes. Curr Opin Immunol 22: 428-434.

Pricop L, Gokhale J, Redecha P, Ng SC, Salmon JE (1999) Reactive oxygen intermediates enhance Fc $\gamma$ receptor signalling and amplify phagocytic capacity. J Immunol 162: 7041-7048.

Rathakrishnan C Tiku ML (1993) Lucigenin-dependant chemiluminescence in articular chondrocytes. Free Radic Biol Med 15: 143-149.

Reichl S, Arnhold J, Knight J, Schiller J, Arnold K (2000) Reactions of Pholasin ${ }^{\circledR}$ with peroxidases and hypochlorus acid. Free Radic Biol Med 28: 1555-1563.

Reichl S, Vocks A, Petkovic M, Schiller J, Arnhold J (2001) The photoprotein Pholasin ${ }^{\circledR}$ as a luminescence substrate for detection of superoxide anion radicals and myeloperoxidase activity in stimulated neutrophils. Free Radical Res 35: 723-733.

Rinaldi M, Moroni P, Paape MJ, Bannerman DD (2007) Evaluation of assays for the measurement of bovine neutrophil reactive oxygen species. Vet Immunol Immunopathol 115: 107-125.

Rutault K, Alderman C, Chain BM, Katz DR (1999) Reactive oxygen species activate human peripheral blood dendritic cells. Free Radic Biol Med 26: 232-238.

Samuni M, Krishna CM, Cook J, Black CDV, Russo A (1991) On radical production by PMAstimulated neutrophils as monitored by luminol-amplified chemiluminescence. Free Radic Biol Med 10: 305-313.

Sanders SP, Harrison SJ, Kuppusomy P, Sylvester JT, Zweier JL (1994) A comparative study of EPR spin and cytochrome $\mathrm{c}$ reduction techniques for the measurement of superoxide anions. Free Radic Biol Med 16: 753-761.

San Jose G, Bidegain J, Robador PA, Diez J, Fortuno A, Zalba G (2009) Insulin-induced NADPH oxidase activation promotes proliferation and matrix metalloproteinase activation in monocytes/macrophages. Free Radic Biol Med 46: 1058-1067. 
Santos TC, Marques AP, Silva SS, Oliveira JM, Mano JF, Castro AG, Reis RL (2007) In vitro evaluation of the behaviour of human polymorphonuclear neutrophils in direct contact with chitosan-based membranes. J Biotechnol 132: 218-226.

Savill J, Fadok V, Henson P, Haslett C (1993) Phagocyte recognition of cells undergoing apoptosis. Immunol Today 14: 131-136.

Schilder AM (2010) Wegeners granulomatosis vasculitis and granuloma. Autoimmun Rev 9: 483-487.

Schmielau J, Finn OJ (2001) Activated granulocytes and granulocyte-derived hydrogen peroxide are the underlying mechanism of suppression of T-cell function in advanced cancer patients. Cancer Res 61: 4756-4760.

Schafer M, Werner S (2008) Oxidative stress in normal and impaired wound repair. Pharmacol Res 58: 165-171.

Schonfelder U, Abel M, Wiegand C, Klemm D, Elsner P, Hipler UC (2005) Influence of selected wound dressings on PMN elastase in chronic wound fluid and their antioxidative potential in vitro. Biomaterials 26: 6664-6673.

Sen KS, Roy S (2008) Redox signals in wound healing. Biochim Biophys Acta 1780: 1348-1361.

Shields AM, Panayi GS, Corrigall VM (2011) Resolution associated molecular patterns (RAMP): RAMParts defending immunological homeostasis. Clin Exp Immunol 165: 292-300.

Shen LW, Gao PJ, Che ZQ, Ji KD, Yin M, Yan C, Berk $\mathrm{BC}, \mathrm{Zhu} \mathrm{DL}$ (2006) NAD(P)H oxidase-derived reactive oxygen species regulate angiotensin-II induced adventitial fibroblast phenotypic differentiation. Biochem Biophys Res Commun 339: 337-343.

Song W, Zhang J, Guo J, Zhang J, Ding F, Li L, Sun Z (2010) Role of the dissolved zinc ion and reactive oxygen species in cytotoxicity of $\mathrm{ZnO}$ nanoparticles. Toxicol Lett 199: 389-397.

Steiling H, Munz B, Werner S, Brauchle M (1999) Different types of ROS-scavenging enzymes are expressed during cutaneous wound repair. Exp Cell Res 247: 484-494.

Storz P (2005) Reactive oxygen species in tumor progression. Front Biosci 10: 1881-1886.

Sutherland K, Mahoney JR, Coury AJ, Eaton JW (1993) Degradation of biomaterials by phagocyte-derived oxidants. J Clin Invest 92: 2360-2367.

Swarnakar NK, Jain AK, Singh RP, Gondugu C, Das M, Jain S (2011) Oral bioavailability, therapeutic efficacy and reactive oxygen species scavenging properties of coenzyme Q10-loaded nanospheres. Biomaterials 32: 6860-6874.

Szpaderska AM, DiPietro LA (2005) Inflammation in surgical wound healing: friend or foe? Surgery 137: 571 573.

Tarr JM, Ding M, Kaul K, Antonell A, Perez-Jurado LA, Chibber R (2012) Cellular crosstalk between TNF $\alpha$, NADPH oxidase, PKC $\beta 2$ and $\mathrm{C} 2 \mathrm{GNT}$ in human leukocytes. Cell Signal 24: 873-878.

Taylor EL, Megson IL, Hasslet C, Rossi AG (2003) Nitric oxide: key regulators of myeloid cell apoptosis. Cell Death Different 10: 418-430.

Taylor GC, Waddington RJ, Moseley R, Williams KR, Embery G (1996) Influence of titanium oxide and peroxy gel on the breakdown of hyaluronan by reactive oxygen species. Biomaterials 17: 1313-1319.

Tlili A, Dupre-Crochet S, Erard M, Nube O (2011) Kinetic analysis of phagosomal production of reactive oxygen species. Free Radical Biol Med 50: 438-447.

Toppo S, Flohé F, Ursini F, Vanin S, Maiorino M (2009) Catalytic mechanism and specificities of glutathione peroxidases: Variations of a basic scheme. Biochim Biophys Acta 1790: 1486-1500.

Tsirogianni AK, Moutsopoulos NM, Moutsopoulos HM (2006) Wound healing: immunological aspects. Injury 37S: S5-S12.

Valle-Prieta A, Conget PA (2010) Human mesenchymal stem cells efficiently manage oxidative stress. Stem Cells Develop 19: 1885-1893.

Van der Vliet A (2008) NADPH oxidases in lung biology and pathology: Host defence enzymes and more. Free Radical Biol Med 44: 938-955.

Vautier S, MacCullum DM, Brown GD (2012) C-type lectin receptors and cytokines in fungal immunity. Cytokine 58: 89-99.

Vilim V, Wilhelm J (1989) What do we measure by a luminol-dependant chemiluminescence of phagocytes. Free Radical Biol Med 6: 623-629.

Ward C, Wong TH, Murray J, Rahman I, Haslett C, Chilvers ER, Rossi AG (2000a) Induction of human neutrophil apoptosis by nitric oxide donors: evidence for a caspase-dependant, cyclic-GMP-independent, mechanism. Biochem Pharmacol 59: 305-314.

Ward RA, Nakamura M, McLeish KR (2000b) Priming of the neutrophil respiratory burst involves p38 mitogen activated protein kinase dependant exocytosis of flavocytochrome b558-containing granules. J Biol Chem 275: 36713-36719.

Wilgus TA (2008) Immune cells in the healing skin wound: influential players at each stage of repair. Pharmacol Res 58: 112-116.

Witko-Sarsat V, Rieu P, Descamps-Latscha B, Lesavre P, Halbwachs-Mecarelli L (2000) Neutrophils : Molecules, functions and pathophysiological aspects. Lab Invest 80: 617-653.

Wood ZA, Schroder E, Harris JR, Poole LE (2003) Structure, mechanism and regulation of peroiredoxins. Trends Biochem Sci 28: 32-40.

Wu Y, Tibrewal N, Birge RB (2006) Phosphatidylserine recognition by phagocytes: a view to kill. Trends Cell Biol 16: 189-197.

Yano K, Ide K, Monomi Y, Yamazoe K, Kudo T (2003) Enhancement of reactive oxygen species production from canine blood leukocytes by human recombinant interleukin-12. Vet Immunol Immunopathol 93:1-8.

Yin JJ, Lao F, Fu PP, Wamer WG, Zhao Y, Wang PC, Qiu Y, Sun Y, Xing G, Dong J, Liang XJ, Chen C (2009) The scavenging of reactive oxygen species and the potential for cell protection by functionalised fullerene biomaterials. Biomaterials 30: 611-621.

Yoo KS, Starnes TW, Deng Q, Huttenlocher A (2011) Lyn is a redox sensor that mediates leukocyte wound attraction in vivo. Nature 480: 109-115. 
Yoo SK, Huttenlocher A (2009) Innate immunity: wound burst $\mathrm{H}_{2} \mathrm{O}_{2}$ signals to leukocytes. Curr Biol 19: R552-R555.

Yoshitomi T, Hirayama A, Nagsaki Y (2011) The ROS scavenging and renal protective effects of $\mathrm{pH}$-responsive nitroxide radical-containing nanoparticles. Biomaterials 32: 8021-8028.

Yoshitomi Y, Yamaguchi Y, Kikuchi A, Nagasaki Y (2012) Creation of a blood-compatible surface: A novel strategy for suppressing blood activation and coagulation using nitroxide radical-containing polymer with reactive oxygen species scavenging ability. Acta Biomater 8: 1323 1329.

Zelko IN, Mariani TJ, Folz RJ (2002) Superoxide dismutatse multigene family: a comparison of the $\mathrm{CuZn}$ -
SOD (SOD1), Mn-SOD (SOD2), and EC-SOD (SOD3) gene structures, evolution and expression. Free Radic Biol Med 33: 337-349.

Zhang WJ, Wei H, Frei B (2009) Genetic deficiency of NADPH oxidase does not diminish, but rather enhances, LPS-induced inflammatory responses in vivo. Free Radic Biol Med 46: 791-798.

Editor's Note: All comments by the reviewers were answered by text changes, hence there is no Discussion with Reviewers section. 